\title{
$\$$ Research Square \\ Factors related to myopia progression in orthokeratology practice: A 2-year follow-up study
}

\section{Shijin Wen}

Xiangya Hospital Central South University

\section{Siqi Ma}

Xiangya Hospital Central South University

Chuchu Xiao

Xiangya Hospital Central South University

Shengfa Hu

Xiangya Hospital Central South University

Xufang Ran

Xiangya Hospital Central South University

Xingping Tan

Xiangya Hospital Central South University

Xiaobo Xia

Xiangya Hospital Central South University

Xia Zhou ( $\square$ doclotuscn@126.com )

Xiangya Hospital Central South University

\section{Research Article}

Keywords: orthokeratology practice, myopia, progression

Posted Date: April 14th, 2021

DOI: https://doi.org/10.21203/rs.3.rs-403353/v1

License: (c) (1) This work is licensed under a Creative Commons Attribution 4.0 International License.

Read Full License 


\section{Abstract}

The incidence of myopia in adolescents is gradually increasing, and orthokeratology has achieved effective effects in controlling the progress of myopia, but the effects are mixed. The retrospective study included 30 monocular orthokeratology (ortho-k) lens-treated adolescents to explore the true effectiveness of ortho-k lenses and 36 binocular ortho-k lenses-treated adolescents to study the influencing factors of ortho-k lenses. After 12 months, among 30 adolescents treated with monocular ortho-k lenses, the average axial elongation in the ortho-k group was significantly less than that in the control group $(P=0.002)$. After 24 months, among 36 adolescents treated binocular ortho-k lenses, the axial elongation in the different initial age groups and different initial myopia groups were significantly different (all $P<0.05$ ). Axial elongation correlated negatively with initial myopia during follow-up periods. In adolescents with myopia, axial elongation can be controlled effectively using an ortho-k lens. Younger children with initial higher myopia will benefit more than older children with initial lower myopia.

\section{Introduction}

In recent years, the prevalence of myopia in adolescents has been increasing year by year, and the age of onset has gradually advanced[1]. Low and moderate myopia is acceptable, while high myopia, especially super high myopia (diopter $\leq \mathbb{\nabla} 8.00 \mathrm{D}$ ) has significant negative effects of the patient's vision and quality of life. Excessive elongation of the axial length might result in complications such as retinal detachment, retinal choroidal atrophy, macular hemorrhage, macular hole, and glaucoma, which will seriously affect vision, the visual quality, and might even cause irreversible visual damage. High myopia has become the main cause of blindness and low vision [2-4]. Studies have shown that the possibility of high adult myopia is associated with an earlier age of onset $[1,5]$. With increasing myopia degree, the anterior chamber becomes deeper and the vitreous cavity and the axial length gradually become longer; therefore, the axial length is one of the most important clinical indicators to measure myopia progression $[6,7]$.

Fortunately, the orthokeratology (ortho-k) lens has shown great advantages in controlling myopia progression in adolescents, and has delayed the increase of myopia by $45 \%$ to $55 \%$, which has been widely recognized by the ophthalmology community and parents [8-11]. However, in our clinical work, we have found that the effects of wearing ortho-k lens on axial elongation in adolescents are different. Some children achieve an ideal effect of controlling axial elongation, whereas some children have an unsatisfactory outcome. Whether the adolescent's own biological factors affect the speed of axial change is a question worthy of discussion.

Therefore, we carried out a study of axial length in adolescents wearing ortho-k lenses, with the aim of determining which baseline factors influence axial length change after ortho-k lens treatment.

\section{Materials And Methods}

\section{Subjects}


Data from 189 adolescents with myopia who attended Xiangya Hospital of the Central South University between June 2014 to October 2018 were analyzed retrospectively. Thirty of them only wore an ortho-k lens in one eye, but not any intervention in the contralateral eye. All subjects finished 1 year of follow-up. Thirty-six of them(72 eyes) wore ortho-k lens in both eyes and finished 2 years of follow-up, but only 71 eyes' data adopted due to one patient losing his/her right ortho-k lens. The 71 eyes were placed in groups with respect to myopia degree, corneal curvature, sex, corneal thickness, and initial age. The sex subgroups comprised male and female; the age subgroups comprised $\geq 13$ years old, 10-13 years old, and 6-10 years old; the myopia subgroups comprised $\geq-3.00 \mathrm{D},-3.00$ to $-6.00 \mathrm{D}$, and $<-6.00 \mathrm{D}$; the corneal thickness subgroups comprised $£ 550 \mu \mathrm{m}$ and $>550 \mu \mathrm{m}$; and the corneal curvature subgroups comprised $€ 42.0 \mathrm{D}, 42.0-44.0 \mathrm{D}$ and $>44.0 \mathrm{D}$.

\section{Inclusion criteria}

Patients who wore ortho-k lenses were aged 6-18 years old; whose eyes with ortho-k lenses had a diopter from $-0.50 \mathrm{D}$ to $-8.00 \mathrm{D}$, whose with-the-rule astigmatism was less than $1.50 \mathrm{D}$; whose against-the-rule astigmatism was less than $1.00 \mathrm{D}$; who could achieve corrected visual acuity in both eyes at 1.0; who could master the method of wearing scientific lenses; who had comprehensive clinical data; and who cooperated with correction treatment, regular review, and follow-up.

Additionally, the pivotal inclusion criteria in contralateral eye study is that the myopia eye had a diopter from $-0.50 D$ to $-8.00 D$ and have an uncorrected visual acuity lower than $20 / 25$, while the contralateral eye have an uncorrected visual acuity of $20 / 25$ or better, had near emmetropia or mild refractive error between $-0.50 \mathrm{D}$ and $+1.25 \mathrm{D}$ and no prior eye disease.

\section{Exclusion criteria}

Patients were excluded from the study if they suffered from hyperopia, amblyopia, and ocular organic diseases; had keratoconus, corneal refractive surgery, glaucoma, dry eye, and ocular diseases in the acute stage of inflammation; or had a history of contact lens or contact lens care solution allergy.

\section{Instruments and materials}

Orthokeratology (Boston XO, oxygen permeability 100, spherical 4-zone lens) was used to apply corneal refractive technology. Topcon (Tokyo, Japan) provided the slit lamp microscope, the non-contact tonometer (CT-800), and the corneal endothelial cell counter (SP-3000P). Medmont (Nunawading, Australia) provided the corneal topographer. Nidek (Tokyo, Japan) provided the corneal pachymeter. Zeiss (Jena, Germany) provided the Iolmaster.

\section{Methods}

The following methods was carried out according to the details provided in [10] with some modifications. This study adhered to the tenets of the Declaration of Helsinki and was approved by the Medical Ethics 
Committee of Xiangya Hospital of the Central South University. All patients and their guardians provided written informed consent.

Before the subjects starting wearing the ortho-k lens (and during follow-up), their corneal endothelial cells, corneal curvature, corneal topography, cyclopleg refraction, breakup time of lacrimal film(BUT), intraocular pressure (IOP), visual acuity (VA), and best-corrected visual acuity (BCVA) were assessed to determine their health status.Atropine Sulfate Eye Gel $1 \%$ (SINQI, China) was administered three times a day for a consecutive 3 days in subjects aged between 6 and 10 years old. Subjects under the age of 10 all referred to a clinical optometrist after 20 days of Atropine administration. For subjects over 10 years old, cycloplegic refraction was performed by the instillation of three drops of Tropicamide phenylephrine eye drops $0.5 \%$ (Santen, Japan) separated 10 min apart and referred to a clinical optometrist the next day for suitable lenses. Myopic progression was estimated by measuring the axial length. The above patient parameters were determined at 1, 7, 30, and 90 days, and at 12 and 24 months after they commenced wearing the lenses. The lenses offered to the subjects will be replaced after 1 year. For these examinations, the ortho-k lenses were removed and three hours later, the corneal topography, corneal integrity, axial length, IOP, cycloplegic refraction, and VA were measured, and the corneal epithelium was subjected to fluorescein staining[12] (Table 1). An observation of abnormal symptoms, including tearing, eye pain, redness, or asphotophobia, redness, eye pain, or tearing occurred, resulted in the cessation of ortho-k lens use for an average of 1 month. The patients received appropriate treatment if the symptoms were severe. The patients could resume wearing the ortho-k lens only when the abnormal symptoms were completely resolved. To ensure that the patients achieved the best possible visual quality, the ortho-k lenses were refitted, taking into account refractive changes and the VA. These ortho-k lens were prescribed by the same technician during follow-up, during which they were also modified taking into account refractive changes and the VA. Using the same IOLMaster each time, the same blinded examiner measured the axial length.

\section{Statistical analysis}

In the present study, the statistical analyses were carried out using SPSS 22.0 (Shanghai Cabit, China). The mean \pm the standard deviation (SD) was used to express the measurement data. An independent sample $t$ test, non-parametric test, analysis of variance (ANOVA), and the least significant difference $t$ test (LSD t-test) were used to compare the differences in axial length among the different groups. A p-value less than 0.05 indicated statistical significance.

\section{Results}

Table 2 shows the baseline biometric data for eyes of the adolescents wearing the ortho-k lenses and the no-lens eyes, determined immediately before they commenced wearing the lenses. Statistically significant differences were noted between the ortho-k lens and control groups at baseline for the axial length, and average sphere diopter (all $\mathrm{P}<0.05$ ), but not for corneal thickness, corneal curvature, cylinder diopter, corneal endothelial cell density, BUT and IOP (all P > 0.05). 
The ocular surface assessment parameters after 1 year of follow-up were showed in Table 3 . In the 30 adolescents with different treatments delivered to both eyes, the axial length was $24.51 \pm 0.83 \mathrm{~mm}$ at baseline and $24.64 \pm 0.76 \mathrm{~mm}$ after 1 year in the ortho-k group; whereas, in the control eyes, the axial length increased from $23.61 \pm 0.78 \mathrm{~mm}$ at baseline to $24.04 \pm 0.75 \mathrm{~mm}$ after 1 year. In the ortho-k group, the axial elongation was $0.13 \pm 0.33 \mathrm{~mm}$, but was lower in the control group at $0.43 \pm 0.39 \mathrm{~mm}$ after 1 year of follow-up $(P=0.002$, paired $t$ test, Table 3$)$. These data suggested that in adolescents, axial elongation could be effectively controlled using ortho-k lenses.

Among the 71 eyes wearing ortho-k lenses who completed the 2-year follow-up, axial elongation was assessed using a homogeneity of variance test in each group. Except for the corneal thickness group, no statistical difference was observed for the sex group, age group, myopia group, and corneal curvature group (all $P>0.05$ ). Therefore, for the sex group, axial elongation was assessed using an independent sample $t$ test; for the corneal thickness group, axial elongation was assessed using a non-parametric test; and for the age group, myopia group, and corneal curvature group, axial elongation was assessed using ANOVA. For the age group, myopia group, and corneal curvature group, axial elongation was significantly different during the 1-year and 2-year period (1 year: age group: $P=0.008$; myopia group: $P=0.002 ; 1$ year: age group: $P=0.000$; myopia group: $P=0.000$ ), which showed that the axial elongation of adolescents wearing ortho-k lens was affected by initial age and initial myopia (Table 4).

Pairwise comparisons were further made for the age and myopia groups to determine the impact on axial elongation of initial age and initial myopia. After 1 year, the average axial elongation values in the three age groups were $0.26 \pm 0.32,0.15 \pm 0.21$, and $-0.14 \pm 0.12 \mathrm{~mm}$. The axial elongation was significantly higher in the first age group compared with that in the third age group $(P=0.002, L S D-t)$. In the low, moderate, and high myopia groups, the average axial elongation values were $0.34 \pm 0.25,0.06 \pm 0.23$, and $-0.00 \pm 0.16 \mathrm{~mm}$, respectively. The axial elongation was significantly higher in the low myopia group compared with that of the moderate myopia $(P=0.000, L S D-t)$ and high myopia $(P=0.001, L S D-t)$ groups. After 2 years, the average axial elongation values in three age groups were $0.45 \pm 0.34,0.33 \pm 0.33$, and $0.02 \pm 0.20 \mathrm{~mm}$, respectively. The axial elongation was significantly lower in the third age group compared with that in the first age group $(P=0.000, L S D-t)$ and second age group $(P=0.010, L S D-t)$. After 2 years, the average axial elongation values in low, moderate, and high myopia groups were $0.60 \pm 0.29$, $0.16 \pm 0.25$, and $0.12 \pm 0.30 \mathrm{~mm}$, respectively. The axial elongation was significantly higher in the low myopia group compared with that of the moderate myopia $(P=0.000, L S D-t)$ and high myopia $(P=0.000$, $L S D-t)$ groups. These results showed that younger adolescents with lower myopia have greater axial elongation than older adolescents with high myopia (Table 5 and 6).

Multiple linear regression analysis of axial elongation and initial age was explored; however, it showed no correlation between initial age and axial elongation over 1- and 2-years of follow-up (1-year: $p=0.114$; 2year: $p=0.061$ ). We constructed a regression of the model using initial myopia, which was used to predict axial elongation and was judged to be fair and significant. Therefore, we performed linear regression of axial elongation and initial myopia. In Figure 1, axial elongation was plotted against initial myopia for 1- and 2-years of follow-up. The equation for the linear regression comprised: $y=0.46+$ 
$0.082 \mathrm{x}\left(R^{2}=0.285, p=0.000\right.$, Fig. 1a) during the 1-year period and $\mathrm{y}=0.751+0.117 \mathrm{x}\left(R^{2}=0.349, p<\right.$ 0.000 , Fig. $1 b$ ) during the 2-year period, which showed that children with higher myopia wearing ortho-k lenses would experience slower axial elongation.

Analysis of variance for multiple-factor-repeated measurements was performed to explore the influence of different time points and different groups on the axial length. Judging by the box plot, the clinical data had no outliers and obeyed a normal distribution according to the Shapiro-Wilk test. After Mauchly's W spherical hypothesis test, $X^{2}(2)=20.909, p=0.000$, multivariate analysis was performed, which showed that there was a statistically significant difference in axial length among different time points at different age groups(all $p=0.000$ ). In addition, there was an interaction between initial age and the duration of wearing the ortho-k lenses for the change in axial length (all $p<0.05$ ). Similarly, after Mauchly's $W$ spherical hypothesis test, $X^{2}(2)=10.849, p=0.004$, multivariate analysis was performed, which showed that there was a statistically significant difference in the axial length among different time points at different myopia groups(all $p=0.000$ ). In addition, there was an interaction between initial myopia and the duration of wearing the ortho-k lenses for the change in axial length (both $p=0.000$ ). There was no interaction between sex, the duration of wearing the ortho-k lenses, corneal curvature, and corneal thickness for the change in axial length. These results showed that compared with older adolescents with initial higher myopia, young adolescents with an initial lower myopia showed a gradual slowing down of axial elongation when using the ortho-k lenses (Fig. 2a,b).

In the current study, most of the adolescents reported experiencing only slight discomfort and no severe corneal conditions were reported.

\section{Discussion}

In recent years, with the development of society, changes in activities and leisure, and increased school work, the incidence of myopia in adolescents has increased year by year. Secondary degeneration resulting from myopia increases the risk of blindness. Therefore, the prevention of myopia progression is very important. Currently, the main non-pharmacological method to control myopia in adolescents is orthokeratology; therefore, it is necessary to determine the effectiveness of orthokeratology and the factors that influence its effects. The results of the present study support the hypothesis that in children wearing an ortho-k lens in one eye but not in the other, there was less axial length elongation in the lenscovered eye than in the naked eye during a 1 year period $(P<0.05)$. In addition axial elongation was affected by, and correlated with, initial age and initial myopia.

Currently, it is believed that orthokeratology might reduce relative periphery hyperopia $[13,14]$ to control axial elongation, which is considered an indicator of myopia progression [6, 7]. Many studies have compared the effectiveness between the ortho-k lenses and other treatments, including rigid gas permeable (RGP) lenses, spectacle glasses, and soft radial refractive gradient contact lenses [15-17]. However, Miri et al. proposed that there was uncontrolled variable, termed "inter-subject difference", during the follow-up periods, which was explained by stating that the differences in the baseline of 
subjects and different environments could accelerate myopic progression in some children [18]. For example, the rate of axial elongation of an individual, the sex ratio in the treatment and control groups, and the external environment, such as excessive close work in some children, could affect the evaluation of effectiveness of orthokeratology to control myopia progression. Therefore, it is necessary to design experiment that allows us to control the important variables to the greatest extent.

There are many baseline factors that influence the controlling effect of ortho-k lenses on axial elongation in adolescents. Studies have shown that myopia progression is negatively related to initial age, possibly because the axial elongation will gradually slow down with older age[19-21]. Although a few studies demonstrated no correlation between axial elongation and initial myopia [22, 23], other studies revealed a negative correlation $[21,24,25]$ and stated that this correlation is possibly associated with the relative peripheral hyperopia defocus $[26,27]$. The hypothesis states that there is a steeper central peripheral cornea in adolescents with higher myopia, which causes less stimulation of retinal relative peripheral hyperopia, thus exerting less control of axial length and consequently, myopia progression[28-30].

In view of the impact of "inter-subject difference", we believe that the contralateral eye design of the present study can control the potential effect of confounding factors on axial elongation to the greatest extent during the follow-up period. The contralateral eye study design could prevent the influence of potential confounding factors, including ethnicity, the study period, initial age, and method of treatment in the control group. Although there are myopic anisometropia and aniso-axial length at baseline between myopia eye and contralateral eye in our study, Deng et al.[31] consider that there is a similar progression rate of myopia and axial length in both eyes for most children during the period of fast progression and eventual stabilization in the Correction of Myopia Evaluation Trial (COMET) cohort. Our results showed a significantly lower axial elongation in the ortho-k group compared with that in the no intervention group at 1 -year of follow-up, which proved that the ortho-k lens was effective to control axial elongation.

We did not observe a significant linear correlation between axial elongation and initial age. During the 1year and 2-year period, the axial elongation of younger children was significantly higher than that of older children, which was comparable to the results reported in the literature cited[10, 19-21]. We also found that the increase in the axial elongation of the younger group gradually slowed down with time, although the eye axial elongation in younger group was greater than that in older group during the 1-year and 2year period. Thus, we believe that younger children would benefit more from wearing ortho-k lenses than older children. This supports the view that ortho-k can reduce the risk of rapid myopia progression significantly, and that younger wearers could experience increased benefit, despite having a higher rate of axial growth [32].

Our study demonstrated that children with lower myopia experienced significantly higher axial elongation compared with children with higher myopia (both moderate and high myopia). In addition, axial elongation and initial myopia correlated significantly during the 1-year and 2-year periods. This study demonstrated that children with higher myopia will experience better control of axial length compared with children with lower myopia. In our study, interestingly, although the axial elongation in lower myopia 
group was greater than that in higher myopia group, there was a trend that rate of increase in axial elongation of the low myopia group gradually slowed down over time compared with that in higher myopia groups, we supposed that children with low myopia will receive more benefit from wearing ortho$\mathrm{k}$ lenses compared with children with higher myopia, but further research will be needed to validate these claims..

The present study had some limitations. First, the study period was not long to enough to investigate the rate of axial elongation of different myopia groups in the long term; therefore, in future studies, a longer follow-up period is recommended. Second, the present study involved a relatively small sample size. Thus, a larger-scale study should be conducted to verify the efficacy and limitations of long-term ortho-k lens use.

\section{Conclusion}

Effective control of axial elongation can be achieved using the orthokeratology lens according to our contralateral eye study design. The ortho-k lens cannot completely halt myopia-related axial elongation in children; however, use of the lens can slow down axial elongation to a certain extent. Over the long term, younger children with lower myopia will benefit more from orthokeratology treatment.

\section{Declarations}

\section{Author Contributions}

WS and ZX designed the study, analyzed the data, and wrote the manuscript. MS, XC, HS, RX, TX, and XX performed the examinations, collected the data, and managed the e study. ZX supervised the study and revised the manuscript. All authors read and approved the final manuscript.

\section{Conflict of Interest Statement}

The authors declare that they have no competing interests.

\section{References}

1. Tay S, Farzavandi S, Tan D. Interventions to Reduce Myopia Progression in Children. Strabismus.25,23-32(2017).

2. Wang J, Ying G, Fu X, Zhang R, Meng J, Gu F, Li J. Prevalence of myopia and vision impairment in school students in Eastern China. BMC Ophthalmol.20,2(2020).

3. Lin LLK, Shih YF, Hsiao CK, Chen CJ. Prevalence of myopia in Taiwanese schoolchildren: 1983 to 2000. Annals of the Academy of Medicine Singapore.33,27(2004).

4. Zadnik K, Sinnott L, Cotter S, Jones-Jordan L, Kleinstein R, Manny R, Twelker J, Mutti D. Prediction of Juvenile-Onset Myopia. JAMA ophthalmology.133,683-689(2015). 
5. Sun Y, Xu F, Zhang T, Liu M, Wang D, Chen Y, Liu Q. Orthokeratology to control myopia progression: a meta-analysis. PLoS One.10,e0124535(2015).

6. Cheung $S$, Cho P. Validity of axial length measurements for monitoring myopic progression in orthokeratology. Invest Ophthalmol Vis Sci.54,1613-1615(2013).

7. Fledelius $\mathrm{H}$, Goldschmidt E. Oculometry findings in high myopia at adult age: considerations based on oculometric follow-up data over 28 years in a cohort-based Danish high-myopia series. Acta Ophthalmol (Copenh).88,472-478(2010).

8. Lee Y, Wang J, Chiu C. Effect of Orthokeratology on myopia progression: twelve-year results of a retrospective cohort study. BMC Ophthalmol.17,243(2017).

9. Santodomingo-Rubido J, Villa-Collar C, Gilmartin B, Gutiérrez-Ortega R, Sugimoto K. Long-term Efficacy of Orthokeratology Contact Lens Wear in Controlling the Progression of Childhood Myopia. Curr Eye Res.42,713-720(2017).

10. He M, Du Y, Liu Q, Ren C, Liu J, Wang Q, Li L, Yu J. Effects of orthokeratology on the progression of low to moderate myopia in Chinese children. BMC Ophthalmol.16,126(2016).

11. Sheng-Fa HU, Zhou X, Tan XP, Xia XB, Centre O, Hospital X, University CS. Efficacy of orthokeratology lens for treatment of juvenile myopic astigmatism. China Journal of Modern Medicine.2015).

12. Bron A, Evans V, Smith J. Grading of corneal and conjunctival staining in the context of other dry eye tests. Cornea.22,640-650(2003).

13. Huang J, Wen D, Wang Q, McAlinden C, Flitcroft I, Chen H, Saw S, Chen H, Bao F, Zhao Y et al. Efficacy Comparison of 16 Interventions for Myopia Control in Children: A Network Meta-analysis. Ophthalmology.123,697-708(2016).

14. Smith $\mathrm{M}$, Walline J. Controlling myopia progression in children and adolescents. Adolescent health, medicine and therapeutics.6,133-140(2015).

15. Swarbrick H, Alharbi A, Watt K, Lum E, Kang P. Myopia control during orthokeratology lens wear in children using a novel study design. Ophthalmology.122,620-630(2015).

16. Zhu M, Feng H, HeX, Zou H, Zhu J. The control effect of orthokeratology on axial length elongation in Chinese children with myopia. BMC Ophthalmol.14,141(2014).

17. Jaime P, Hari M, Jesús A, Lluisa Q, Miguel FR, M. G-MJ. Myopia Control with a Novel Peripheral Gradient Soft Lens and Orthokeratology: A 2-Year Clinical Trial. Biomed Research International.2015,10(2015).

18. $\mathrm{Na} \mathrm{M}$, Yoo A. The effect of orthokeratology on axial length elongation in children with myopia: Contralateral comparison study. Jpn J Ophthalmol.2018).

19. Chen R, Chen Y, Lipson M, Kang P, Lian H, Zhao Y, McAlinden C, Huang J. The Effect of Treatment Zone Decentration on Myopic Progression during Or-thokeratology. Curr Eye Res.45,645-651(2020).

20. Lee E, Lim D, Chung T, Hyun J, Han J. Association of Axial Length Growth and Topographic Change in Orthokeratology. Eye \& contact lens.44,292-298(2018). 
21. Wang B, Naidu R, Qu X. Factors related to axial length elongation and myopia progression in orthokeratology practice. PLoS One.12,e0175913(2017).

22. Cho P, Cheung S. Retardation of myopia in Orthokeratology (ROMIO) study: a 2-year randomized clinical trial. Invest Ophthalmol Vis Sci.53,7077-7085(2012).

23. Hiraoka T, Kakita T, Okamoto F, Takahashi H, Oshika T. Long-term effect of overnight orthokeratology on axial length elongation in childhood myopia: a 5-year follow-up study. Invest Ophthalmol Vis Sci.53,3913-3919(2012).

24. Fu A, Chen X, Lv Y, Wang S, Shang L, Li X, Zhu Y. Higher spherical equivalent refractive errors is associated with slower axial elongation wearing orthokeratology. Contact lens \& anterior eye : the journal of the British Contact Lens Association.39,62-66(2016).

25. Zhong Y, Ke L, Qiong W, Liu F. Orthokeratology lens for management of myopia in anisometropic children: A contralateral study. Contact lens \& anterior eye : the journal of the British Contact Lens Association.43,40-43(2020).

26. Smith E, Kee C, Ramamirtham R, Qiao-Grider Y, Hung L. Peripheral vision can influence eye growth and refractive development in infant monkeys. Invest Ophthalmol Vis Sci.46,3965-3972(2005).

27. Smith E, Huang J, Hung L, Blasdel T, Humbird T, Bockhorst K. Hemiretinal form deprivation: evidence for local control of eye growth and refractive development in infant monkeys. Invest Ophthalmol Vis Sci.50,5057-5069(2009).

28. Charm J, Cho P. High myopia-partial reduction ortho-k: a 2-year randomized study. Optometry and vision science : official publication of the American Academy of Optometry.90,530-539(2013).

29. Gifford K, Gifford P, Hendicott P, Schmid K. Stability of peripheral refraction changes in orthokeratology for myopia. Contact lens \& anterior eye : the journal of the British Contact Lens Association.43,44-53(2020).

30. Kang P, Swarbrick H. Peripheral refraction in myopic children wearing orthokeratology and gaspermeable lenses. Optometry and vision science : official publication of the American Academy of Optometry.88,476-482(2011).

31. Deng L, Gwiazda J, Manny R, Scheiman M, Weissberg E, Fern K, Weise K. Limited change in anisometropia and aniso-axial length over 13 years in myopic children enrolled in the Correction of Myopia Evaluation Trial. Invest Ophthalmol Vis Sci.55,2097-2105(2014).

32. Cho P, Cheung S. Protective Role of Orthokeratology in Reducing Risk of Rapid Axial Elongation: A Reanalysis of Data From the ROMIO and TO-SEE Studies. Invest Ophthalmol Vis Sci.58,14111416(2017).

\section{Tables}

Table 1. Grading of corneal fluorescein staining [12] 


\begin{tabular}{|c|c|c|}
\hline Grade & Degree of injury & Treatment \\
\hline 0 & A few dots of staining & No Treatment \\
\hline I & Increased spots showing a & Continuing lens wear and \\
\hline & scatter pattern & \multirow{2}{*}{$\begin{array}{l}\text { using a small amount of eye drops for } \\
\text { cornea repair until the disappearance of } \\
\text { symptoms }\end{array}$} \\
\hline II & $\begin{array}{l}\text { Obvious clinical manifestations, dense } \\
\text { and diffuse spots }\end{array}$ & \\
\hline III & $\begin{array}{l}\text { A large number of stippling stains, } \\
\text { marked amounts of aggregation and } \\
\text { fusion }\end{array}$ & $\begin{array}{l}\text { Stopping treatment, adjusting } \\
\text { the lens, and giving } \\
\text { symptomatic medication until }\end{array}$ \\
\hline IV & $\begin{array}{l}\text { Diffuse stippling stains of the } \\
\text { whole cornea, mass fusion or } \\
\text { even complete epithelial loss }\end{array}$ & $\begin{array}{l}\text { the disappearance of } \\
\text { symptoms }\end{array}$ \\
\hline
\end{tabular}

Table 2. Demographic and biometric measures (mean \pm SD) at baseline for the subjects between ortho-k group and the control group

\begin{tabular}{|c|c|c|c|}
\hline & Ortho-k & Control & $\bar{P}$ \\
\hline Number of eyes & 30 & 30 & \\
\hline $\begin{array}{l}\text { Age (y) } \\
\text { Sphere (D) }\end{array}$ & $\begin{array}{l}11.67 \pm 0.35 \text { (range } 8-16) \\
-1.99 \pm 0.20(\text { range }-0.70-\end{array}$ & $0.27 \pm 0.09$ (range $+1.25-$ & $-0_{0}^{*}$ \\
\hline Cylinder (D) & $-0.40 \pm 0.06$ (range $-1.50-$ & $-0.16 \pm 0.14$ (range $+1.50-$ & 0.12 \\
\hline Corneal thickness (mm) & $\begin{array}{l}0.00) \\
564.03 \pm 5.56 \quad \text { (range } \\
512.00-617.00)\end{array}$ & $\begin{array}{l}-1.50) \\
562.06 \\
\left.513.00-\frac{5}{623.00}\right)\end{array}$ & 0.12 \\
\hline Corneal curvature (D) & $\begin{array}{l}42.88 \pm 0.28 \text { (range } 39.50 \\
-46.75 \text { ) }\end{array}$ & $\begin{array}{l}42.65 \pm 0.26 \text { (range } 39.50 \\
-46.25 \text { ) }\end{array}$ & 0.13 \\
\hline $\begin{array}{l}\text { Corneal endothelial cell } \\
\text { density }\left(\text { cells } / \mathrm{mm}^{2}\right)\end{array}$ & $\begin{array}{l}3084.99 \\
47.36 \text { (range } 2685.00 \\
3548.30 \text { ) }\end{array}$ & $\begin{array}{l}3100.52 \\
53.87 \text { (range } 2619.70 \begin{array}{l} \pm \\
3378.80 \text { ) }\end{array}\end{array}$ & 0.52 \\
\hline BUT(s) & $\begin{array}{l}11.3 \pm 0.18 \text { (range } 9.00 \text { - } \\
12.00 \text { ) }\end{array}$ & $\begin{array}{l}10.8 \pm 0.27 \text { (range } 8.00 \text { - } \\
13.00 \text { ) }\end{array}$ & 0.07 \\
\hline $\mathrm{IOP}(\mathrm{mmHg})$ & 13.47 (rance $1000-1800)^{ \pm}$ & 13.80 (range $1100-1700)^{ \pm}$ & 0.22 \\
\hline $\begin{array}{l}\text { the initial axial } \\
\text { length }(\mathrm{mm})\end{array}$ & 0.83 (range $22.67-25.84$ ) & 0.78 (range $21.87-25.20$ ) & $0.00^{*}$ \\
\hline
\end{tabular}

${ }^{*} \mathrm{P} \leq 0.05$ (obtained from paired $t$ tests)

Table 3. Ocular surface assessment parameters (mean \pm SD) after 1 year of follow-up for the subjects between ortho-k group and the control group 


\begin{tabular}{|c|c|c|c|}
\hline & Ortho-k & Control & $\bar{P}$ \\
\hline $\begin{array}{l}\text { Number of eyes } \\
\text { Corneal thickness (mm) }\end{array}$ & 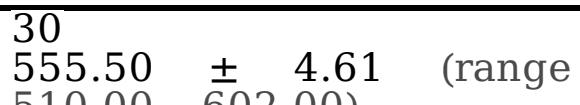 & $30754.03 \pm 4.96 \quad$ (range & 0.13 \\
\hline Corneal curvature (D) & $42.01 \pm 0.42$ (range 38.59 & $42.66 \pm 0.39$ (range 40.43 & 0.07 \\
\hline $\begin{array}{l}\text { Corneal endothelial cell } \\
\left.\text { density (cells } / \mathrm{mm}^{2}\right)\end{array}$ & $\begin{array}{l}3029.87 \\
50.02 \text { (range } 2524.40 \\
3524.30 \text { ) }\end{array}$ & $\begin{array}{l}3076.48 \text { (range } 2478.70 \\
50.69 \text { - } \\
3531.30 \text { ) }\end{array}$ & 0.08 \\
\hline BUT(s) & $\begin{array}{l}9.97 \pm 0.06 \text { (range } 9.00 \text { - } \\
10.00 \text { ) }\end{array}$ & $\begin{array}{l}9.87 \pm 0.09 \text { (range } 8.00- \\
10.00 \text { ) }\end{array}$ & 0.38 \\
\hline IOP(mmHg) & $\begin{array}{l}13.60 \\
0.33 \text { (range } 10.00-17.00 \stackrel{ \pm}{ }\end{array}$ & $\begin{array}{l}13.70 \\
0.36 \text { (range } 11.00-17.00 \text { ) }\end{array}$ & 0.75 \\
\hline Axial length(mm) & 24.64 (range $23.16-25.85$ ) & 24.04 (range $22.27-25.23)$ & $0.00^{*}$ \\
\hline Axial elongation (mm) & $\begin{array}{l}0.13 \pm 0.33 \text { (range }-1.04- \\
0.69)\end{array}$ & $\begin{array}{l}0.43 \pm 0.39 \text { (range }-0.20- \\
0.88)\end{array}$ & $0.002^{*}$ \\
\hline
\end{tabular}

${ }^{*} \mathrm{P} \leq 0.05$ (obtained from paired $t$ tests)

Table 4. Axial Length and changes in axial length from baseline during the 1-year and 2-year period 


\begin{tabular}{|c|c|c|c|c|c|c|c|c|}
\hline actor & $\overline{\mathrm{N}}$ & $\begin{array}{c}\text { the initial } \\
\text { axial } \\
\text { length }(\mathrm{mm})\end{array}$ & $\begin{array}{l}\text { After 1 } \\
\text { year } \\
(\mathrm{mm})\end{array}$ & $\begin{array}{c}\text { Axial } \\
\text { elongation } \\
(\mathrm{mm})\end{array}$ & $P$ & $\begin{array}{l}\text { After 2 } \\
\text { year } \\
(\mathrm{mm})\end{array}$ & $\begin{array}{c}\text { Axial } \\
\text { elongation } \\
(\mathrm{mm})\end{array}$ & $P$ \\
\hline iender & & & & & 0.425 & & & 0.980 \\
\hline Male & 37 & $25.26 \pm 1.03$ & $\begin{array}{c}25.41 \pm \\
0.94\end{array}$ & $\begin{array}{l}0.14 \pm \\
0.23\end{array}$ & & $\begin{array}{c}25.60 \pm \\
0.91\end{array}$ & $\begin{array}{c}0.34 \pm \\
0.36\end{array}$ & \\
\hline Female & 34 & $24.94 \pm 0.95$ & $\begin{array}{c}25.13 \pm \\
0.83\end{array}$ & $\begin{array}{c}0.20 \pm \\
0.32\end{array}$ & & $\begin{array}{c}25.28 \pm \\
0.85\end{array}$ & $\begin{array}{c}0.34 \pm \\
0.34\end{array}$ & \\
\hline ge & & & & & $0.008^{*}$ & & & $0.002^{*}$ \\
\hline ears $^{6-10}$ & 31 & $24.49 \pm 0.74$ & $\begin{array}{c}24.74 \pm \\
0.66\end{array}$ & $\begin{array}{l}0.25 \pm \\
0.32\end{array}$ & & $\begin{array}{c}24.93 \pm \\
0.70\end{array}$ & $\begin{array}{c}0.45 \pm \\
0.34\end{array}$ & \\
\hline $\begin{array}{l}10-13 \\
\text { ears }\end{array}$ & 30 & $25.36 \pm 0.74$ & $\begin{array}{c}25.51 \pm \\
0.68\end{array}$ & $\begin{array}{l}0.15 \pm \\
0.21\end{array}$ & & $\begin{array}{c}25.70 \pm \\
0.70\end{array}$ & $\begin{array}{l}0.33 \pm \\
0.33\end{array}$ & \\
\hline :13 years & 10 & $26.27 \pm 1.08$ & $\begin{array}{c}26.24 \pm \\
1.04\end{array}$ & $\begin{array}{c}-0.04 \pm \\
0.12\end{array}$ & & $\begin{array}{c}26.28 \pm \\
1.04\end{array}$ & $\begin{array}{c}0.02 \pm \\
0.20\end{array}$ & \\
\hline Tyopia & & & & & $0.000^{*}$ & & & $0.000^{*}$ \\
\hline$\geq-3.00$ & 29 & $24.44 \pm 0.74$ & $\begin{array}{c}24.78 \pm \\
0.69\end{array}$ & $\begin{array}{l}0.34 \pm \\
0.25\end{array}$ & & $\begin{array}{c}25.04 \pm \\
0.70\end{array}$ & $\begin{array}{c}0.60 \pm \\
0.29\end{array}$ & \\
\hline $\begin{array}{l}-3.00 \text { to } \\
3.00 \mathrm{D}\end{array}$ & 35 & $25.38 \pm 0.73$ & $\begin{array}{c}25.44 \pm \\
0.69\end{array}$ & $\begin{array}{l}0.06 \pm \\
0.23\end{array}$ & & $\begin{array}{c}25.54 \pm \\
0.77\end{array}$ & $\begin{array}{l}0.16 \pm \\
0.25\end{array}$ & \\
\hline , $>-6.00$ & 7 & $26.49 \pm 1.12$ & $\begin{array}{c}26.49 \pm \\
1.10\end{array}$ & $\begin{array}{c}-0.00 \pm \\
0.16\end{array}$ & & $\begin{array}{c}26.61 \pm \\
1.10\end{array}$ & $\begin{array}{c}0.12 \pm \\
0.30\end{array}$ & \\
\hline \multicolumn{4}{|c|}{ orneal thickness } & & 0.142 & & & 0.166 \\
\hline 550 & 35 & $25.03 \pm 0.95$ & $\begin{array}{c}25.26 \pm \\
0.79\end{array}$ & $\begin{array}{c}0.23 \pm \\
0.34\end{array}$ & & $\begin{array}{c}25.44 \pm \\
0.83\end{array}$ & $\begin{array}{c}0.41 \pm \\
0.40\end{array}$ & \\
\hline$\underset{m}{>} 550$ & 36 & $25.18 \pm 1.06$ & $\begin{array}{c}25.29 \pm \\
0.99\end{array}$ & $\begin{array}{c}0.11 \pm \\
0.17\end{array}$ & & $\begin{array}{c}25.45 \pm \\
0.96\end{array}$ & $\begin{array}{c}0.27 \pm \\
0.28\end{array}$ & \\
\hline \multicolumn{4}{|c|}{ orneal curvature } & & 0.050 & & & 0.505 \\
\hline$\leq \quad 42.0$ & 30 & $25.79 \pm 0.85$ & $\begin{array}{c}25.89 \pm \\
0.77\end{array}$ & $\begin{array}{c}0.11 \pm \\
0.22\end{array}$ & & $\begin{array}{c}26.07 \pm \\
0.75\end{array}$ & $\begin{array}{c}0.28 \pm \\
0.35\end{array}$ & \\
\hline $\begin{array}{l}42.0- \\
4.0 \mathrm{D}\end{array}$ & 28 & $24.79 \pm 0.77$ & $\begin{array}{c}24.95 \pm \\
0.68\end{array}$ & $\begin{array}{c}0.16 \pm \\
0.24\end{array}$ & & $\begin{array}{c}25.15 \pm \\
0.65\end{array}$ & $\begin{array}{c}0.37 \pm \\
0.40\end{array}$ & \\
\hline$>\quad 44.0$ & 13 & $24.23 \pm 0.73$ & $\begin{array}{c}24.56 \pm \\
0.64\end{array}$ & $\begin{array}{l}0.33 \pm \\
0.38\end{array}$ & & $\begin{array}{l}24.63 \pm \\
0.65\end{array}$ & $\begin{array}{l}0.40 \pm \\
0.22\end{array}$ & \\
\hline
\end{tabular}

${ }^{*} \mathrm{P} \leq 0.05$ (obtained from analysis of variance (ANOVA))

Table 5. Pairwise comparison of mean difference in axial length between different age groups 


\begin{tabular}{cccc}
\hline Age group (I) & Age group (J) & The mean difference in axial length (I-J)/mm & $P$ \\
\hline 12th month & & & \\
1 & 2 & $0.11 \pm 0.06$ & 0.089 \\
\cline { 2 - 4 } 2 & 3 & $0.30 \pm 0.09$ & $0.002^{*}$ \\
& 1 & $-0.11 \pm 0.06$ & 0.089 \\
\hline 3 & 3 & $0.18 \pm 0.09$ & 0.055 \\
& 1 & $-0.30 \pm 0.09$ & $0.002^{*}$ \\
\hline 24 th month & 2 & $-0.18 \pm 0.09$ & 0.055 \\
\hline 1 & 2 & $0.12 \pm 0.08$ & 0.162 \\
\hline 2 & 3 & $0.43 \pm 0.12$ & $0.000^{*}$ \\
& 1 & $-0.12 \pm 0.08$ & 0.162 \\
3 & 3 & $0.31 \pm 0.12$ & $0.010^{*}$ \\
& 1 & $-0.43 \pm 0.12$ & $0.000^{*}$ \\
\hline & 2 & $-0.31 \pm 0.12$ & $0.010^{*}$ \\
\hline
\end{tabular}

1: the age subgroups 6-10 years old, 2: the age subgroups 10-13 years old, 3: the age subgroups $\geq 13$ years old; ${ }^{*} \mathrm{P} \leq 0.05$ (obtained from a least significance difference $t$ test (LSDt))

Table 6. Pairwise comparison of mean difference of axial length between different myopia groups

\begin{tabular}{cccc}
\hline Myopia group (I) & Myopia group (J) & The mean difference in axial length (I-J)/mm & $P$ \\
\hline 12 th month & 2 & $0.27 \pm 0.06$ & $0.000^{*}$ \\
\cline { 2 - 4 } & 3 & $0.34 \pm 0.10$ & $0.001^{*}$ \\
2 & 1 & $-0.27 \pm 0.06$ & $0.000^{*}$ \\
\hline 3 & 3 & $0.07 \pm 0.10$ & 0.496 \\
\hline 24 th month & 1 & $-0.34 \pm 0.10$ & $0.001^{*}$ \\
1 & 2 & $-0.07 \pm 0.10$ & 0.496 \\
\hline 2 & 2 & $0.44 \pm 0.07$ & $0.000^{*}$ \\
& 3 & $0.48 \pm 0.11$ & $0.000^{*}$ \\
3 & 1 & $-0.44 \pm 0.07$ & $0.000^{*}$ \\
\hline & 3 & $0.04 \pm 0.11$ & 0.720 \\
\hline & 1 & $-0.48 \pm 0.11$ & $0.000^{*}$ \\
\hline & 2 & $-0.04 \pm 0.11$ & 0.720 \\
\hline
\end{tabular}

1: the myopia subgroups $\geq-3.00 \mathrm{D}, 2$ : the myopia subgroups -3.00 to $-6.00 \mathrm{D}, 3$ : the myopia subgroups $<-6.00 \mathrm{D} ;{ }^{*} \mathrm{P} \leq 0.05$ (obtained from a least significance difference $t$ test (LSD-t))

\section{Figures}


$\mathbf{a}$

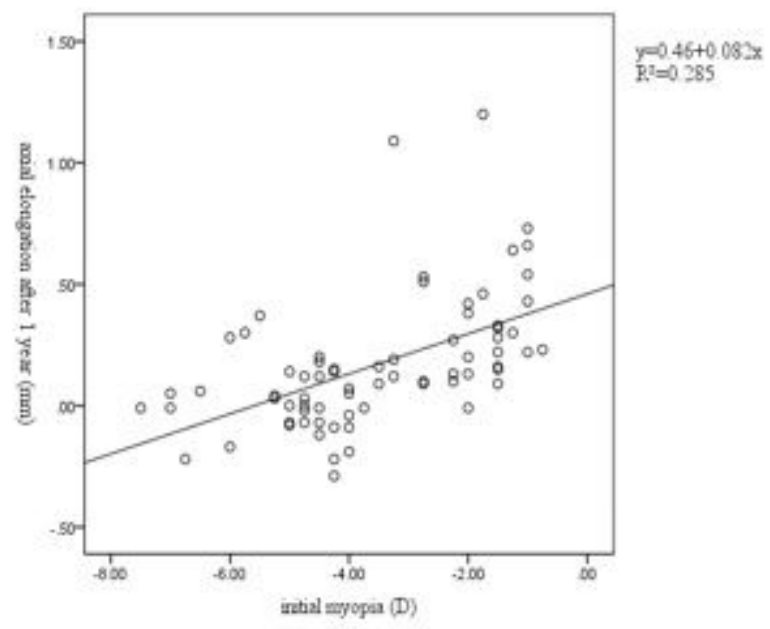

b

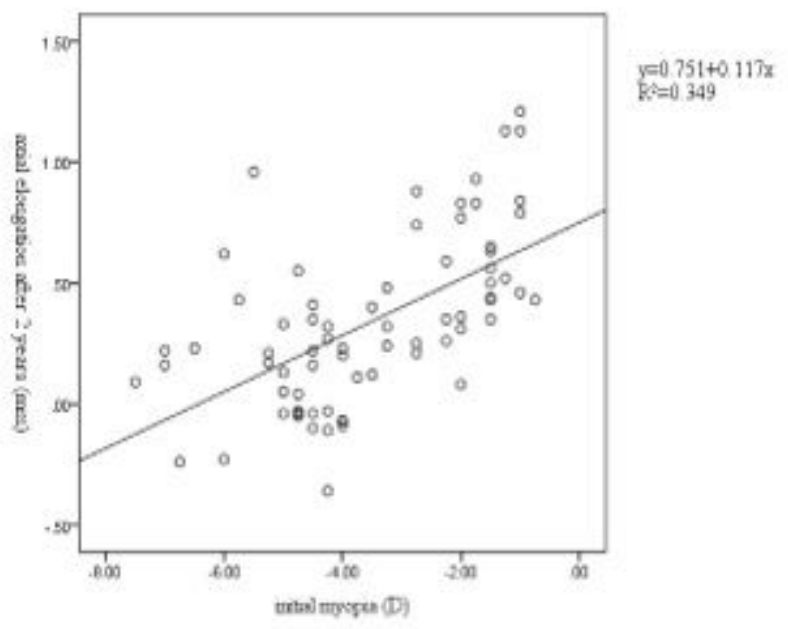

Figure 1

Scatter plots showing correlations of axial elongation with initial myopia during 1 year period(a) and during 2 year period(b).

$\mathbf{a}$

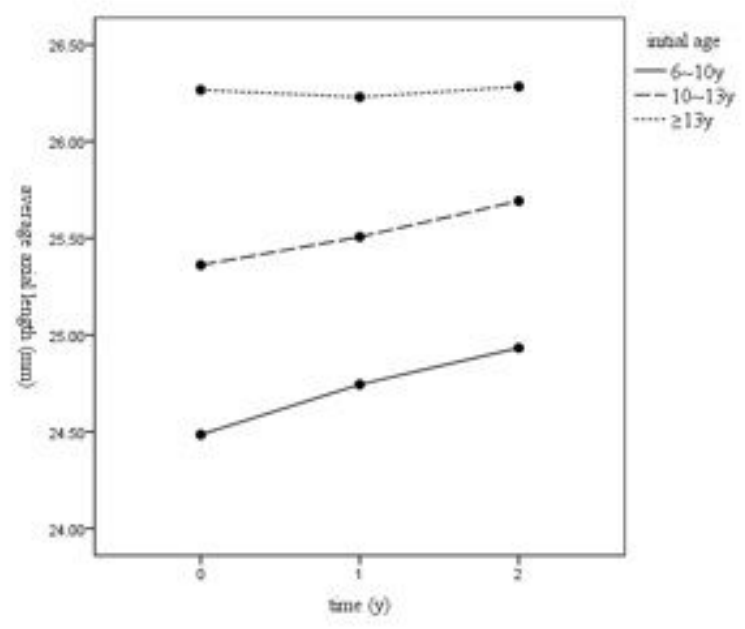

b

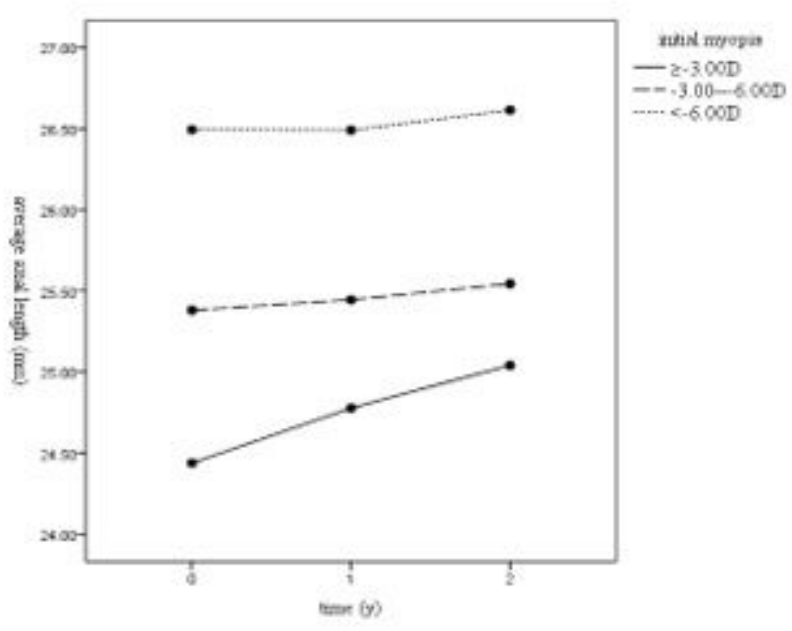

Figure 2

The change trend of the axial length at different initial age(a) and initial myopia(b) at the 1 day before wearing ortho-k lens, 1 year and 2 years after wearing ortho-k lens.

\section{Supplementary Files}

This is a list of supplementary files associated with this preprint. Click to download. 
- originaldata.xlsx

Page 16/16 